\title{
Age-Dependent Prevalence of Malaria in Akeddei Community in South-South Nigeria
}

\author{
Roland I. Funwei ${ }^{1,2 *}$, Anthony B. Akpe ${ }^{3}$, Ayakeme Tonkiri ${ }^{4}$, Dressman E. Akuegbe ${ }^{1}$, An- \\ thony Gilbert ${ }^{1}$ and Botimi-ama Funwei ${ }^{3}$ \\ ${ }^{1}$ Department of Pharmacy Technician Studies, Bayelsa State College of Health Technology, Otuogidi- \\ Ogbia, Yenagoa \\ ${ }^{2}$ Department of Pharmacology and Therapeutics, University of Ibadan \\ ${ }^{3}$ Department of Community Health Sciences, Bayelsa State College of Health Technology, Otuogidi- \\ Ogbia, Yenagoa \\ ${ }^{4}$ School of Foundation Studies, Bayelsa State College of Health Technology, Otuogidi-Ogbia, \\ Yenagoa
}

\begin{abstract}
*Correspondence should be addressed to Roland I. Funwei: okporu2@gmail.com
Received 14h May 2021; Revised 16th June 2021; Accepted 2nd July 2021

(C) 2021 Funwei et al. Licensee Pan African Journal of Life Sciences an official publication of Faculty of Basic Medical Sciences, Ladoke Akintola University of Technology, Ogbomoso. This is an Open Access article distributed under the terms of the Creative commons Attribution License (https://creativecommons.org/licenses/BY/4.0), which permits unrestricted use, distribution, and reproduction in any medium, provided the original work is properly cited.
\end{abstract}

\begin{abstract}
Background: Malaria is highly endemic in Nigeria, making malaria morbidity and mortality a leading public health challenge. The most at risk population of malaria attack is under-five years' children. However, malaria is presumptively treated in older age groups. This study aimed to determine the age-dependent prevalence of malaria amongst three age groups in a rural community in south-south Nigeria.
\end{abstract}

Methods: A community-based cross-sectional survey comprising febrile and afebrile participants $(\mathrm{n}=$ 300) were randomly selected and included for the study. The study participants were grouped into three groups: under-five years old children $(n=100)$, older children of aged $6-15$ years $(n=100)$ and 16 years and above $(\mathrm{n}=100)$. Malaria Rapid Diagnostic Tests (RDTs) and Giemsa-stained microscopy were used for malaria diagnosis and parasite detection. Clinical and demographic parameters as well as malaria prevalence were analyzed. The level of statistical significance was considered at $\rho=0.05$

Results: Malaria prevalence in the under-five age group was $73 \%$ by RDTs and $49 \%$ by microscopy. For the $6-15$ years, the prevalence of malaria was $60 \%$ and $43 \%$ by RDTs and microscopy respectively while RDTs accounted for $38 \%$ and microscopy $17 \%$ for the 16 years and above group.

Conclusion: Artemisinin-based combination therapies (ACTs) administration to older children and adults should be based on parasitological confirmation of suspected cases with at least malaria RDTs to reduce drug pressure.

Keywords: Malaria Epidemiology, Age-dependent Malaria Prevalence, RDTs, Microscopy, Nigeria 


\subsection{INTRODUCTION}

The burden of Plasmodium falciparum malaria and the relationship between the age-pattern of malaria morbidity and transmission intensity suggest that severe malaria is more concentrated in younger age groups in areas of high malaria transmission $[1,2]$. In settings with high malaria transmission intensity, it has been reported that the incidence of clinical attacks peaks in early childhood (under five years) and then declines rapidly with increasing age as a result of several episodes of malaria attacks and acquisition of clinical immunity in such populations [3, 4]. Conversely, in areas of moderate transmission intensity, the age of peak transmission is in older children, in contrast, in populations exposed to very low transmission level or epidemic malaria, the risk of infection remains constant across all age groups [5]. Therefore, the age pattern of malaria incidence can serve as an indicator for naturally acquired immunity in the malaria-endemic population $[6,7]$.

Globally, the most vulnerable age group to malaria deaths are children under five years old [8]. The number of deaths from malaria tends to decrease with age, with those over 70 years old accounting for less than four percent [9]. When age categories are combined, children under 14 years old account for approximately 80 percent of mortality [9].

However, most fever cases are considered as malaria infections. They are treated as such without parasitological confirmation among all age groups in rural communities in sub-Saharan Africa [10], especially in Nigeria which carries a disproportionate burden of the infection $[11,12]$. The overuse or inappropriate use of antimalarial medications is on the increase in Nigeria. Artemisinin-based combination therapies (ACTs) are sold over the counter. They are readily purchased and consumed without proper prescription and diagnosis [13, 14], leading to self-medication, and increasing the risk of the emergence of antimalarial drug selection pressure [12].

There is a paucity of published data on the evaluation of age-dependent malaria prevalence and distribution at Akeddei community in Bayelsa State. Proper understanding of the epidemiology of the disease among at-risk groups in the study population is warranted. This study reports the age-dependent clinical malaria prevalence and distribution in a rural village in the southern part of Nigeria.

\subsection{METHODOLOGY}

\subsection{The Study Design and Location}

A community-based cross-sectional study design was conducted from June to October 2019 in a rural village (Akeddei community). Akeddei is situated in the riverine area of the oil rich Niger Delta region (Bayelsa state, Sagbama LGA) of Nigeria. It is located between latitudes $4^{\circ} 55{ }^{\prime} \mathrm{N}$ and longitudes $6^{\circ} 04^{\prime} \mathrm{E}$. The study terrain is composed of thick forests and freshwater swamp with a large area of land flooded for most of the year. There is an intense rainfall from March to October and a very short dry season observed from November to February each year [15]. The main occupation of the inhabitants is fish farming. The peculiar features of the study location serve as favorable breeding site for mosquito and malaria transmission.

\subsection{Study Population}

The study population comprised febrile and afebrile under five-year children of both sexes, older children (615 years), and adults (16 years and above) within the community. A total of 300 participants (100 participants per age group) was included for random malaria screening using RDTs and microscopy

\subsection{Parasitological Assessment}

\subsubsection{Microscopy}

A finger-prick blood sample was collected from each participant for thick- blood smears stained with $10 \%$ fresh Giemsa-stain following standard procedure for parasite identification and quantification by expert [16]. A thick blood smear was considered negative only after 100 consecutive high power fields were screened and free of malaria parasite. Slides were read by an expert microscopist at the Malaria Laboratory, Institute for Advanced Medical Research and Training (IAMRAT), University of Ibadan.

\subsubsection{Rapid Diagnostic Tests (RDTs)}

The Carestart ${ }^{\mathrm{TM}}$ (Access Bio, Inc. USA) brand of the RDT was used for this study. The test preparation and interpretation was carried out according to manufacturer's instructions. Reading and interpretation of test results was done within the specified 15-20 min test win- 
dow. The test result was positive when the test and control lines were visible in their respective test windows, but negative when only the control line is visible and invalid when the control line is not visible. Faint test lines were also considered positive. Haemoglobin level was also estimated by using the Tallquist method by comparing the colour of the blood with the standards provided by the manufacturers in percentages.

\subsection{Ethical Consideration}

Ethical approval for this study was obtained from Bayelsa State Ministry of Health. A verbal informed consent was obtained from all participants (parents/guardians in the case of minors) before any study relatedprocedures were carried out. Information about participants was concealed with utmost confidentiality while participation was voluntary.

\subsection{Data Analysis}

Data were entered into Microsoft Excel and IBM SPSS (version 20) for analysis. The Mean and standard deviation (SD) of clinical, demographic parameters and malaria prevalence were analyzed and compared. The prevalence of malaria among the different age groups was compared using Chi-square. Statistical level of significance was p-value $<0.05$.

\subsection{RESULTS}

One hundred participants were enrolled in each age group. The mean age of the participants in the under-five year group was $2 \pm 1$ years, the $6-15$ years group was 9 \pm 2 years while the mean age for the 16 years and above group was $43 \pm 16$ years respectively. In the under-five years group $47 \%$ of the participants were males while $53 \%$ were females. Similarly, in the $6-15$ years and 16 years and above groups, $46 \%$ and $27 \%$ were males while $54 \%$ and $73 \%$ were female. The body temperatures ranged from $36.0^{\circ} \mathrm{C}-39.5^{\circ} \mathrm{C}$ in all the three groups while the mean body weights $(\mathrm{kg})$ were $12.9 \pm 5.6$ (under five years), $27.9 \pm 11.1$ ( $6-15$ years) and $60.6 \pm 10.2$ (16 years and above) respectively. Haemoglobin $(\mathrm{Hb})$ level was $9.3 \pm 2.3 \%$ (under five years), $10.8 \pm 1.8 \%$ (6-15 years) and $13.3 \pm 1.2 \%$ (16 years and above). Parasite density range was between 40 to 148934 while geometric mean was 1696, 494 and 546 respectively (Table 1).

The age-pattern of malaria prevalence and distribution in the under-five group was $73 \%$ by RDTs and $49 \%$ by mi- croscopy. For the $6-15$ years, malaria prevalence was $60 \%$ by RDTs and $43 \%$ by microscopy. RDTs accounted for $38 \%$ and microscopy $17 \%$ for the 16 years and above

Table 1. Demographic and clinical characteristics of the study participants

\begin{tabular}{llll}
\hline Variable & $\begin{array}{l}\text { Under 5yrs } \\
\text { N= 100 }\end{array}$ & $\begin{array}{l}\mathbf{6} \text {-15yrs } \\
\mathbf{N}=\mathbf{1 0 0}\end{array}$ & $\begin{array}{l}\text { 16yrs \& } \\
\text { Above }\end{array}$ \\
\hline Age (Years) & $2 \pm 1$ & $9 \pm 2$ & $43 \pm 16$ \\
Sex (M : F) & M: $47 \%$ & M: $46 \%$ & M: $27 \%$ \\
Temperature $\left({ }^{\circ} \mathrm{C}\right)$ & $36.7 \pm 0.7$ & $36.5 \pm 0.5$ & $36.5 \pm 0.5$ \\
Weight $(\mathrm{kg})$ & $12.9 \pm 5.6$ & $27.9 \pm 11.1$ & $60.6 \pm 10.2$ \\
Hb Level $(\%)$ & $9.3 \pm 2.3$ & $10.8 \pm 1.8$ & $13.3 \pm 1.2$ \\
Geometric Mean & 1696 & 494 & 546 \\
\hline
\end{tabular}

age group. The difference in the proportion of malaria prevalence and distribution between the under-five and the other groups (6-15yrs and >16yrs) was statistically significant $(\rho=0.000)$ for RDTs and microscopy respectively (Table 2).

Malaria prevalence was higher in females than their male in all the age groups while presence of fever positively influenced parasitaemia (Table 2).

\subsection{DISCUSSION}

Children under five years and pregnant women are the most vulnerable population for malaria infection $[17,18]$. Our study corroborated under five year's children as the highest group with malaria prevalence in the study population ( $73 \%$ and $49 \%$ ) by RDT and microscopy respectively. Although, in areas of high malaria transmission intensity, it has been reported that a decline in malaria incidence is associated with age $[19,20]$ which is thought to be as a result of acquisition of clinical immunity due to intense exposure in early life $[3,4]$. Our findings show that the prevalence of malaria decreases as children grow older and into adulthood (table 2). Thus antimalarial drug administration to older children and adults in high malaria transmission settings should be carefully considered with parasitological confirmation. Inappropriate malaria case management is one of the most typical public health challenges among rural dwellers. All febrile illnesses characterized by fever are assumed to be malaria infections and are treated with antimalarial drugs without de- 
Table 2. Gender and Fever Status on Malaria Prevalence

\begin{tabular}{|c|c|c|c|}
\hline Variable & RDT +ve (\%) & MP +ve (\%) & $\begin{array}{l}\text { RDT/MP } \\
+ \text { ve }(\%)\end{array}$ \\
\hline \multicolumn{4}{|c|}{ Under 5 Year } \\
\hline \multicolumn{4}{|l|}{ Sex: } \\
\hline Male & $34(46.6)$ & $19(38.8)$ & $53(43.4)$ \\
\hline Female & $39(53.4)$ & $30(61.2)$ & $69(56.6)$ \\
\hline Total & $73(100)$ & 49 (100) & $122(100)$ \\
\hline \multicolumn{4}{|c|}{ Fever Status: } \\
\hline Present & $51(69.9)$ & $37(75.5)$ & $88(72.1)$ \\
\hline Absent & $22(30.1)$ & $12(24,5)$ & $34(27.9)$ \\
\hline Total & $73(100)$ & 49 (100) & $122(100)$ \\
\hline \multicolumn{4}{|c|}{$6-15$ Years } \\
\hline \multicolumn{4}{|l|}{ Sex: } \\
\hline Male & $18(30)$ & $19(44.2)$ & 37 (35.9) \\
\hline Female & $42(70)$ & $24(55.8)$ & $66(64.1)$ \\
\hline Total & $60(100)$ & $43(100)$ & $103(100)$ \\
\hline \multicolumn{4}{|c|}{ Fever Status: } \\
\hline Present & $39(65.0)$ & $27(62.8)$ & $66(64.1)$ \\
\hline Absent & $21(35.0)$ & $16(37.2)$ & $37(35.9)$ \\
\hline Total & $60(100)$ & $43(100)$ & $103(100)$ \\
\hline \multicolumn{4}{|c|}{16 years and above } \\
\hline \multicolumn{4}{|l|}{ Sex: } \\
\hline Male & $9(23.7)$ & $5(29.4)$ & $14(25.5)$ \\
\hline Female & $29(73.3)$ & $12(70.6)$ & $41(74.5)$ \\
\hline Total & $38(100)$ & $17(100)$ & $55(100)$ \\
\hline \multicolumn{4}{|c|}{ Fever Status: } \\
\hline Present & $27(71.1)$ & $10(58.8)$ & $37(67.3)$ \\
\hline Absent & $11(28.9)$ & $7(41.2)$ & $18(32.7)$ \\
\hline Total & $38(100)$ & $17(100)$ & $55(100)$ \\
\hline
\end{tabular}

finitive diagnosis [21].Though, the age-dependent decrease in malaria prevalence could be attributable to the fact that older individuals may have developed acquired immunity against Plasmodium falciparum malaria resulting from several episodes of malaria infection. Similar findings were reported in Nigeria [22], Malawi [23] and other malaria endemic areas [24,25]. Conversely, some studies have reported otherwise as malaria incidence was low in children less than five years [26]. This could result of effective utilization of malaria preventive measures such as sleeping under insecticide-treated bed nets and indoor residual spraying with good knowledge and adherence to malaria preventive methods. Ironically, the study population has poor knowledge about utilizing malaria preventive methods such as the non-use of insecticide treated bed nets and other vector control mechanisms in our study area, consistent with previous reports [27]. Despite the free distribution of long-lasting insecticidetreated nets in the study area (Akeddei community) by the government and other interventionist agencies, most individuals use the bed nets for farming activities such as using the nets for fishing and sieving, during cassava processing in the study area. The under-utilization of bed nets and other preventive mechanisms in the evaluated study population exposes all age groups to malaria infection, especially the under-five age group. The inappropriate consumption of antimalarial drugs by older children and adults may stimulate parasite selection pressure and subsequently, emergence of resistant parasites in the population.

Gender-based analysis of malaria prevalence in the study population shows higher malaria infections in females across all age categories than their male counterparts. This finding was consistent with previous studies [28,29] but was contradicted by an adult male bias in clinical malaria in hypo-endemic regions of India [30]. It is unclear if male-biased clinical malaria is associated with malaria hypo-endemic regions while female-biased clinical malaria is associated with hyper-endemic areas. Although it has been argued that adult males are more likely to stay outdoors than adult females, and hence more likely to be bitten by infected mosquitoes, this seems unlikely as the biting pattern of infected mosquitoes has been reported to be host sex-independent [31].

A limitation of the study is the small sample size to represent each age group of the study due to financial constraints. Although, the data gives baseline information on age-wise malaria prevalence in the area. However, larger sample size is required for clearer malaria epidemiological surveillance in the study population as our findings could not be used to make a generalized statement confidently.

This study shows that malaria is age-dependent with the highest burden in the under-five years age group with a steady decline in older age groups in the study population. 
There is a need for proper health education and sensitization on the use of malaria preventive methods to reduce malaria burden in under-five children and the inappropriate antimalarial drug intake by older children and adults in the study population.

\section{Acknowledgement}

We thank all study participants for taking part in the study. More thanks to the parents and caregivers of the under five years children. Special thanks to the community head and the microscopists (Mrs. Bolatito Akinyele) from the Malaria Laboratory, Institute for Advanced Medical Research and Training, University College Hospital, University of Ibadan, Ibadan. our sincere appreciation to Prof. Catherine O. Falade for providing the Rapid Diagnostic Tests (RDTs) kits for the study.

\section{Conflict of interest}

The Authors declare that there is no conflict of interest

\section{Authors' Contribution}

RIF conceived and designed the study, contributed to data collection, data analysis tools, analysis of data and manuscript writing. ABA, AG, performed data collection, contributed to data analysis tools and manuscript writing. AT contributed to data analysis, analysis of data and reviewed the scientific content of the manuscript. DEA, BF contributed to data collection, data analysis tools, analysis of data and manuscript writing. All authors approved the final version of the manuscript

\section{References}

1. Carneiro I, Roca-Feltrer A, Griffin JT, Smith L, Tanner M, Schellenberg JA, et al. Age-Patterns of Malaria Vary with Severity, Transmission Intensity and Seasonality in Sub-Saharan Africa: A Systematic Review and Pooled Analysis. PLoS ONE [Internet]. 2010 Feb 1; 5(2): PLoS ONE 5(2): e8988. https://doi.org/10.1371/ journal.pone.0008988Available from: https:// www.ncbi.nlm.nih.gov/pmc/articles/PMC2813874/

2. Roca-Feltrer A, Carneiro I, Smith L, Schellenberg JRA, Greenwood B, Schellenberg D. The age patterns of severe malaria syndromes in sub-Saharan Africa across a range of transmission intensities and seasonality settings. Malar J. 2010 Oct 13; 9(1):282.
3. Griffin JT, Ferguson NM, Ghani AC. Estimates of the changing age-burden of Plasmodium falciparum malaria disease in sub-Saharan Africa. Nat Commun. 2014 Feb 11; 5(1):1-10.

4. Rono J, Färnert A, Murungi L, Ojal J, Kamuyu G, Guleid F, et al. Multiple clinical episodes of Plasmodium falciparum malaria in a low transmission intensity setting: exposure versus immunity. BMC Med. 2015 May 13; 13:114.

5. Kleinschmidt I, Sharp B. Patterns in age-specific malaria incidence in a population exposed to low levels of malaria transmission intensity. Trop Med Int Health. 2001; 6 (12):986-91.

6. Aponte JJ, Menendez C, Schellenberg D, Kahigwa E, Mshinda H, Vountasou P, et al. Age Interactions in the Development of Naturally Acquired Immunity to Plasmodium falciparum and Its Clinical Presentation. PLOS Med. 2007 Jul 31; 4(7):e242.

7. Doolan DL, Dobaño C, Baird JK. Acquired Immunity to Malaria. Clin Microbiol Rev. 2009 Jan; 22(1):13-36.

8. WHO. World malaria report 2019. WHO, Geneva: https:// www.who.int/publications-detail/world-malaria-report2019.

9. Abdullah S, Adazu K, Masanja H, Diallo D, Hodgson A, Ilboudo-Sanogo E, et al. Patterns of Age-Specific Mortality in Children in Endemic Areas of Sub-Saharan Africa. Am J Trop Med Hyg. 2007 Dec; 77(6 Suppl):99-105.

10. Dalrymple U, Cameron E, Arambepola R, Battle KE, Chestnutt EG, Keddie SH, et al. The contribution of nonmalarial febrile illness co-infections to Plasmodium falciparum case counts in health facilities in sub-Saharan Africa. Malar J. 2019 Jun 11; 18(1):195.

11. Falade CO, Orimadegun AE, Michael OS, Dada-Adegbola HO, Ogunkunle OO, Badejo JA, et al. Consequences of restricting antimalarial drugs to rapid diagnostic testpositive febrile children in south-west Nigeria. Trop Med Int Health TM IH. 2019; 24(11):1291-300.

12. Oladosu OO, Oyibo WA. Overdiagnosis and Overtreatment of Malaria in Children That Presented with Fever in Lagos, Nigeria [Internet]. ISRN Infectious Diseases. 2012 [cited 2021 Feb 13]. Available from: https:// www.hindawi.com/journals/isrn/2013/914675/

13. Falade PCO. Assessment of cardiac safety following artemether-lumefantrine (AL) or artesunate- amodiaquine (ASAQ) treatment of acute uncomplicated falciparum malaria in children from Ibadan Southwest Nigeria. Afr J Med Med Sci. 2020 Sep 14; 49(2):173-80.

14. Okoro RN, Jamiu MO. The Cross-Sectional Evaluation of 
the Use of Artemisinin-Based Combination Therapy for Treatment of Malaria Infection at a Tertiary Hospital in Nigeria [Internet]. Journal of Tropical Medicine. 2018 [cited 2021 Feb 13]. Available from: https:// www.hindawi.com/journals/jtm/2018/2025858/

15. Ike PC. Trend Analysis of Climate Change Factors and Yield of Yam in Bayelsa State, Nigeria. J Agric Food Sci. 2012; 10(1):18-26.

16. Trape JF. Rapid evaluation of malaria parasite density and standardization of thick smear examination for epidemiological investigations. Trans R Soc Trop Med Hyg. 1985; 79(2):181-4.

17. Afoakwah C, Deng X, Onur I. Malaria infection among children under-five: the use of large-scale interventions in Ghana. BMC Public Health. 2018 Apr 23; 18(1):536.

18. Chilanga E, Collin-Vézina D, MacIntosh H, Mitchell C, Cherney K. Prevalence and determinants of malaria infection among children of local farmers in Central Malawi. Malar J. 2020 Aug 27; 19(1):308.

19. Nkumama IN, O’Meara WP, Osier FHA. Changes in Malaria Epidemiology in Africa and New Challenges for Elimination. Trends Parasitol. 2017 Feb 1; 33(2):128-40.

20. O’Meara WP, Mwangi TW, Williams TN, McKenzie FE, Snow RW, Marsh K. Relationship Between Exposure, Clinical Malaria, and Age in an Area of Changing Transmission Intensity. Am J Trop Med Hyg. 2008 Aug; 79 (2):185-91.

21. Elven J, Dahal P, Ashley EA, Thomas NV, Shrestha P, Stepniewska K, et al. Non-malarial febrile illness: a systematic review of published aetiological studies and case reports from Africa, 1980-2015. BMC Med. 2020 Sep $21 ; 18(1): 279$.

22. Nwaorgu OC, Orajaka BN. Prevalence of Malaria among Children $1-10$ Years Old in Communities in Awka North Local Government Area, Anambra State South East Nigeria. Afr Res Rev. 2011;5(5):264-81.

23. Barua P, Beeson JG, Maleta K, Ashorn P, Rogerson SJ. The impact of early life exposure to Plasmodium falciparum on the development of naturally acquired immunity to malaria in young Malawian children. Malar J. 2019 Jan $18 ; 18(1): 11$.
24. Pinkevych M, Petravic J, Chelimo K, Kazura JW, Moormann AM, Davenport MP. The Dynamics of Naturally Acquired Immunity to Plasmodium falciparum Infection. PLOS Comput Biol. 2012 Oct 18; 8(10):e1002729.

25. Stanisic DI, Fowkes FJI, Koinari M, Javati S, Lin E, Kiniboro B, et al. Acquisition of Antibodies against Plasmodium falciparum Merozoites and Malaria Immunity in Young Children and the Influence of Age, Force of Infection, and Magnitude of Response. Infect Immun. 2015 Feb 1;83(2):646-60.

26. Mawili-Mboumba DP, Akotet MKB, Kendjo E, Nzamba $\mathrm{J}$, Medang MO, Mbina J-RM, et al. Increase in malaria prevalence and age of at risk population in different areas of Gabon. Malar J. 2013 Jan 2; 12(1):3.

27. Khadanga S, Thatoi P K, Mohapatra B N, Mohapatra N, Mohanty CBK, Karuna T. Differences. Severe Falciparum Malaria-Difference in Mortality among Male and Nonpregnant Females. J Clin Diagn Res JCDR. 2014 Dec; 8(12):MC01-MC04.

28. Sandie SM, Sumbele IUN, Tasah MM, Kimbi HK. Malaria parasite prevalence and Haematological parameters in HIV seropositive patients attending the regional hospital Limbe, Cameroon: a hospital-based cross-sectional study. BMC Infect Dis. 2019 Nov 21;19(1):988.

29. Pathak S, Rege M, Gogtay NJ, Aigal U, Sharma SK, Valecha N, et al. Age-Dependent Sex Bias in Clinical Malarial Disease in Hypoendemic Regions. PLoS ONE [Internet]. 2012 [cited 2021 Feb 12]; 7(4). Available from: https://www.ncbi.nlm.nih.gov/pmc/articles/ PMC3338423/

30. Golenda C.F, Solberg V. B, Burge R, Gambel J. M and Wirtz R. A. Gender-related efficacy difference to an extended duration formulation of topical N, N-diethyl-mtoluamide (DEET) [Internet]. The American journal of tropical medicine and hygiene. 1999 [cited 2021 Feb 12]. Available from: https://pubmed.ncbi.nlm.nih.gov/ $10348243 /$

31. Singhaboot, Y., Keayarsa, S., Piaraksa, N., Phumratanaprapin, W., Kunawut, P., Dondorp, A., and Chotivanich, K. Temperature Dependence of Plasmodium falciparum Erythrocytic Stage Development. Am. J. Trop. Med. Hyg. 2019. 100, 1191-1195. 